\title{
Case Report: Severe Accidental Organophosphorus Poisoning in Two Children
}

\author{
Alireza Aminisefat ${ }^{1}$ (D), Khadijeh Saravani2 ${ }^{* *}$ (D) Mahdieh Saravani $^{3}$ \\ 1. Student Research Committee, Zabol University of Medical Sciences, Zabol, Iran. \\ 2. Department of Medical, Assistant Professor of Forensic Medicine and Toxicology, Zabol University of Medical Sciences, Zabol, Iran. \\ 3. Department of Pediatric, Children and Adolescent Health Research center, Zahedan University of Medical Sciences, Khash, Iran.
}

\section{(c) (1) (3)}

Article info:

Received: 24 Apr 2020

First Revision: 04 May 2020

Accepted: 06 May 2020

Published: 05 Nov 2020

\section{Keywords:}

Organophosphorus compounds, Pesticides, Chlorpyrifos,

Autonomic nervous system diseases
Citation: Aminisefat A, Saravani K, Saravani M. Severe Accidental Organophosphorus Poisoning in Two Children. International Journal of Medical Toxicology and Forensic Medicine. 2020; 10(4):30128. https://doi.org/10.32598/ijmtfm.v10i4.30128

https://doi.org/10.32598/ijmtfm.v10i4.30128

\section{Introduction}

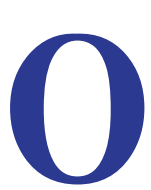

rganophosphorus (OP) compounds have vigorous anticholinesterase activity and are commonly used as insecticides and pesticides [1]. OP poisoning is a global health problem due to occupational, accidental, or intentional exposure (to commit suicide), especially in developing countries, and poses a threat to human health [2]. According to the previous studies, OP poisoning can kill up to 200000 people per year with $10.20 \%$ mortality [3]. These compounds are absorbed from the oral, respiratory, and transdermal pathways and expose people to poisoning [4]. In acute OP poisoning, the most common causes of death are usually respiratory failure and cardiac arrest, which is caused by its cholinergic effects [5]. In this case study, we reported a 3-year-old patient who developed weakness in upper and lower limb movements without respiratory failure and loss of consciousness after being poisoned with OP compounds and her 4-year-old sister, who just lost consciousness.

\section{Case presentation}

The patients were two sisters, aged 3 and 4, brought to the emergency department with nausea and vomiting. They had inadvertently eaten agricultural pesticides. The poisoning occurred 3 hours before the patients were visited in the hospital. The poison used was chlor-

* Corresponding Author:

Khadijeh Saravani, MD.

Address: Department of Medical, Assistant Professor of Forensic Medicine and Toxicology, Zabol University of Medical Sciences, Zabol, Iran.

Tel: +98 (543) 2225402

E-mail:dr.kh.saravani93@gmail.com 
pyrifos, which was brought to the hospital the next day by their family.

At the time of presentation, they were well oriented and cooperative, with a Glasgow Coma Score (GCS) of 15 . Both had tachycardia, and their other vital signs were stable (BP: 100/60 and 100/65 mm Hg, respiratory rate: 22 and 20 breath per minute, the temperature was $37.5^{\circ} \mathrm{C}$ and $37.4^{\circ} \mathrm{C}$, SPO2: $98 \%$ and $99 \%$ on room air for 3-year-old and 4-year-old sisters, respectively). They had a runny nose but no runny eyes or mouth. There was no diarrhea or fasciculation, and examination of the pupils and lungs was normal. The results of the other tests were generally not significant.

After 5 hours from the onset of symptoms, the 3-yearold patient experienced a decrease in the level of consciousness. The lab results showed leukocytosis of 24.3 x $109 / 1$ (normal range 4 to 10 x $103 / \mathrm{mm} 3$ ), normal liver function, renal function, and serum levels of sodium and potassium. Other laboratory results were within normal limits. No conduction abnormalities were observed on an electrocardiogram. Arterial blood gas analysis showed a $\mathrm{pH}$ of 7.37, $\mathrm{PO} 2$ of $30.9 \mathrm{~mm} \mathrm{Hg}$ and $\mathrm{PCO} 2$ of $36.4 \mathrm{~mm} \mathrm{Hg}$, and $\mathrm{SPO} 2$ of $58.4 \%$. Her brain $\mathrm{CT}$ and chest $\mathrm{x}$-ray were normal (Figure 1).

Shortly afterward, the 4-year-old patient lost her consciousness. The lab results showed leukocytosis of $14.2 \times 109 / 1$ (normal range 4 to $10 \times 103 / \mathrm{mm} 3$ ), and other laboratory results were within normal limits. Arterial blood gas analysis showed a $\mathrm{pH}$ of 7.42, $\mathrm{PO} 2$ of $42.6 \mathrm{~mm} \mathrm{Hg}, \mathrm{PCO} 2$ of $29.7 \mathrm{~mm} \mathrm{Hg}$, and SPO2 of $80.2 \%$. Their serum and blood cell acetylcholinesterase (AChE) levels were not assayed due to the test's unavailability at our facility.

The patients regained consciousness after receiving $0.5 \mathrm{mg}$ atropine. After 5 minutes, they lost consciousness and received $1 \mathrm{mg}$ atropine again. By reducing their consciousness level, they received $2 \mathrm{mg}, 4 \mathrm{mg}$, and then $4 \mathrm{mg}$ atropine in 5 minutes intervals until they got fully conscious. To continue treatment, they received continuous drip of $1 \mathrm{mg}, 0.5 \mathrm{mg}$, and then $0.25 \mathrm{mg}$ in 12 hours intervals, and then atropine was discontinued. Twenty-four hours after stopping atropine, high-fat foods, preferably milk, were started for the patients. After 24 hours of eating high-fat foods, the 4-year-old girl general condition improved, and her test results were normal. So she was discharged from the hospital in good general condition. But the 3-year-old girl had a weakness in the movement of the upper and lower limbs. And this paralysis and weakness in limbs movement continued for 4 days after discontinuation of atropine.

\section{Discussion}

OP poisoning is a concern, especially in rural areas due to the availability of insecticides and pesticides. OPs compounds cause an irreversible inhibition of the esterase enzymes, especially AChE. This enzyme hydrolyzes the neurotransmitter acetylcholine (ACh) in synapses and red blood cell membranes [6]. This defect causes the accumulation of $\mathrm{ACh}$ and overstimulation of its receptors in synapses of the autonomic nervous system, CNS, and neuromuscular junctions [7]. Thus the symptoms of this poisoning are muscarinic and nicotinic side effects. The muscarinic symptoms include myosis, lacrimation, excessive salivation, bradycardia, diarrhea, and wheezing. The nicotinic symptoms include hypertension, fasciculation, and tachycardia [8]. However, patients can experience central effects such as fatigue, dizziness, and in severe cases, loss of consciousness, paroxysmal convulsion, respiratory failure, and even death [9] (Table 1).

In this study, on the fourth day after admission to the hospital, the 3-year-old patient experienced weakness in the movements of the upper and lower limbs known as intermediate syndrome (IMS) complications. IMS is

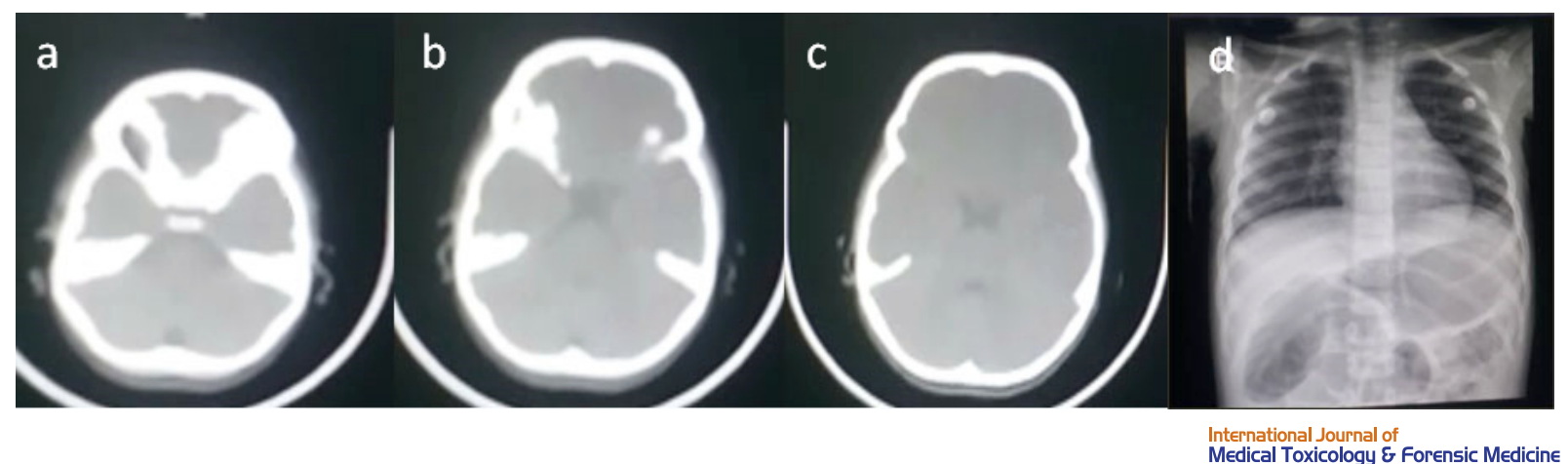

Figure 1. Radiographic imaging of the 3-year-old patient. (a-c) Brain CT and (d) Chest x-ray findings were normal. 
Table 1. Symptoms and signs of organophosphorus poisoning (acute cholinergic phase of OP poisoning)

\begin{tabular}{|c|c|c|}
\hline Central Receptors & Nicotinic Receptors & Muscarinic Receptors \\
\hline Dizziness & Hypertension & Hypotension \\
\hline Loss of consciousness & Tachycardia & Bradycardia \\
\hline Paroxysmal convulsion & Weakness & Myosis \\
\hline Coma & Fasciculation & Excessive salivation \\
\hline Respiratory failure & & Bronchospasm \\
\hline Tremors & & Cough \\
\hline Absent reflexes & & Nausea/vomiting \\
\hline Anxiety & & Wheezing \\
\hline Ataxia & & Lacrimation \\
\hline & & Bronchorrhoea \\
\hline & & Rhinorrhea \\
\hline
\end{tabular}

a complication of poisoning with OP compounds. It is usually seen 2-4 days after the disappearance of the acute symptoms of the cholinergic phase of OP poisoning but before organophosphate-induced delayed polyneuropathy. IMS symptoms can manifest as weakness of the respiratory muscles such as the diaphragm, intercostal and cervical muscles and rarely the weakness of the proximal muscles of the limbs [10]. In this study, two sisters were poisoned with chlorpyrifos, which is a relatively low-toxic organophosphate, and the occurrence of the secondary IMS of chlorpyrifos is infrequent [11]. In IMS, recovery usually occurs within 4 to 18 days, and sensory capacities are generally not impaired [12].

There is still no consensus on the pathophysiology of IMS. Yet, some studies have suggested that the dynamic of AChE and desensitization of ACh receptors is the basis for the development of IMS [10]. Many studies have indicated that the nature of OP compounds, the severity of poisoning, and inadequate oxime therapy can play a role in creating IMS [13]. In this article, a 3-year-old patient developed weakness in limb movements, but her sister was discharged without any specific symptoms. Since the primary treatment for both was atropine, the severity of the poisoning seems to play a critical role in the development of IMS. However, considering IMS only cannot be convincing due to insufficient treatment with oxime.
The muscarinic receptor antagonist (atropine) and oxime AChE reactivators (pralidoxime) are used as the main drugs for the treatment of OP poisoning [14]. Studies have shown that in the treatment of OP poisoning, hemoperfusion and continuous injection of atropine increase the survival rate of patients and reduces the reactivation time of cholinesterase, thus reducing the incidence of complications [15]. We do not have pralidoxime in this center and the adjacent center, so we used atropine as the main drug in treating these patients.

\section{Conclusion}

OP poisoning manifests with an acute cholinergic syndrome, IMS, and delayed polyneuropathy, which IMS and delayed neuropathy do not occur acutely and are observed with a delay. Therefore, it is necessary to pay special attention to these complications in the poisoning with OP compounds. We do not have pralidoxime in this center, and we cannot use it in OP poisoning. However, it is not clear how much pralidoxime can prevent IMS.

\section{Ethical Considerations}

\section{Compliance with ethical guidelines}

This study was approved by the Ethics Committee of Zabol University of Medical Sciences. 


\section{Funding}

This research did not receive any grant from funding agencies in the public, commercial, or non-profit sectors.

\section{Author's contributions}

Data collection and Data analysis Khadijeh Saravani and Mahdieh Saravani; Writing the manuscript: Alireza Aminisefat; Review, editing, approve the final version of the manuscript: All authors.

\section{Conflict of interest}

The authors declared no conflict of interest.

\section{Acknowledgements}

The author is grateful to the of these patients' families for their cooperation.

\section{References}

[1] Morris CM, Savy C, Judge SJ, Blain PG. Acute Toxicity of Organophosphorus Compounds. In: Balali-Mood M. Abdollahi M. (eds). Basic Clin Toxicol Organophos Comp. Springer, London; 2014. (pp. 45-78). [DOI:10.1007/978-14471-5625-3_3]

[2] Ali P, Anwer A, Bashir B, Jabeen R, Haroon H, Makki K. Clinical pattern and outcome of organophosphorus poisoning. J Liaq Uni Med Health Sci. 2012; 11(1):15-8 https://applications.emro.who.int/imemrf/J_Liaquat Univ_Med_Health_Sci/J_Liaquat_Univ_Med_Health_ Sci_2012_11_1_15_18.pdf

[3] Prajapati T, Prajapati K, Tandon R, Merchant S. Acute chemical and pharmaceutical poisoning cases treated in civil hospital, Ahmedabad: One year study. Asia Pac J Med Toxicol. 2013; 2(2):63-7. [DOI:10.22038/APJMT.2013.869]

[4] Malla G, Basnet B, Vohra R, Lohani SP, Yadav A, Dhungana $V$. Parenteral organophosphorus poisoning in a rural emergency department: A case report. BMC Res Notes. 2013; 6(1):524. [DOI:10.1186/1756-0500-6-524] [PMID] [PMCID]

[5] Eddleston M, Buckley NA, Checketts H, Senarathna L, Mohamed F, Sheriff MR, et al. Speed of initial atropinisation in significant organophosphorus pesticide poisoning: A systematic comparison of recommended regimens. J Toxicol Clin Toxicol. 2004; 42(6):865-75. [DOI:10.1081/CLT200035223] [PMID] [PMCID]

[6] Cander B, Dur A, Yildiz M, Koyuncu F, Girisgin AS, Gul M, et al. The prognostic value of the Glasgow coma scale, serum acetylcholinesterase and leukocyte levels in acute organophosphorus poisoning. Ann Saudi Med. 2011; 31(2):163-6 [DOI:10.4103/0256-4947.78203] [PMID] [PMCID]
[7] Lotti M. Clinical toxicology of anticholinesterase agents in humans. Hayes' Handbook of Pesticide Toxicology: Elsevier; 2010. p. 1543-89. [DOI:10.1016/B978-0-12-3743671.00072-0]

[8] Alen B. Biochemical abnormalities in OPC poisoning and its prognostic significance. KAP Viswanatham Government Medical College: Tiruchirappalli; 2017.

[9] Gunnell D, Eddleston M, Phillips MR, Konradsen F. The global distribution of fatal pesticide self-poisoning: Aystematic review. BMC public health. 2007; 7(1):357. [DOI:10.1186/1471-2458-7-357] [PMID] [PMCID]

[10] Umakanth M. Intermediate Syndrome following organophosphate poisoning: Review article. Asia Pac J Med Toxicol. 2019; 8(1):19-24.

[11] Malkarnekar S, Naveen L, Adam SR. Organophosphate toxicity presenting with cholinergic crisis, intermediate syndrome and delayed polyneuropathy in succession: A rare presentation. Int J Med Toxicol Foren Med. 2014; 4(4):145-8. [DOI:10.22037/ijmtfm.v4i4(Autumn).5925]

[12] De Lima Teixeira I, Garcia Zanati Bazan S, Schelp AO, Luvizutto GJ, De Lima FD, Bazan R. Abnormal spontaneous eye movements as initial presentation of organophosphate poisoning. Tremor Other Hyperkinet Mov (N Y). 2017; 7:445. [DOI:10.7916/D80865WS] [PMID] [PMCID]

[13] Manohar TP, Khobragade H. Organophosphorus Compound Induced 'intermediate syndrome'. Asia Pac J Med Toxicol. 2018; 7(2):52-3. https://www.sid.ir/en/Journal/ ViewPaper.aspx?ID=703153

[14] Eddleston M, Chowdhury FR. Pharmacological treatment of organophosphorus insecticide poisoning: the old and the (possible) new. Br J Clin Pharmacol. 2016; 81(3):46270. [DOI:10.1111/bcp.12784] [PMID] [PMCID]

[15] Jiang S-z, Ma B-e, Liu C, Wang R. Clinical efficacy of intravenous infusion of atropine with micropump in combination with hemoperfusion on organophosphorus poisoning. Saudi J Biol Sci. 2019; 26(8):2018-21. [DOI:10.1016/j. sjbs.2019.08.010] [PMID] [PMCID] 